This work will be published elsewhere in greater detail.

\section{O. D. Kowlessar}

K. I. Axtman

L. H. HEMPELmanN

Divisions of Experimental Radiology and Radiation Biology,

University of Rochester

School of Medicine and Dentistry, Rochester, New York.

$$
\text { July } 8 .
$$

${ }^{2}$ Kowlessar, O. D., Altman, K. I., and Hempelmann, L. H., Arch. Biochem., 43, 240 (1953).

a Allfrey, V., and Mirsky, A. E., J. Gen. Physiol., 36, 227 (1952)

${ }^{3}$ Dabrowska, W., Cooper, E. J., and Laskowski, M., J. Biol. Chem., $177,991(1949)$

"Gilbert, L. M., Overend, W. G., and Webb, M., Exp. Cell Res., 11, 349 (1951)

${ }^{5}$ Kay, E. R. M., Dounce, A. L., and Simmons, N. S., J. Amer. Chem Soc., 74, 1724 (1952).

\section{A Disturbance of Tryptophan Metabolism in Congenital Hypoplastic Anæmia}

THE clinical entity originally designated as congenital hypoplastic anæmia ${ }^{1}$ and more recently termed erythrogenesis imperfecta ${ }^{2}$ is a rare type of anæmia characterized by an erythroid hypoplasia of the bone marrow, by normocytic and normochromic circulating red cells, and by the lack of response to any of the known erythropoietic agents. In the course of some metabolic studies conducted on one such patient whose anæmia was diagnosed shortly after birth and who had been studied for four years by one of the authors (G.M.), a strongly bluishfluorescent substance was noted in the urine. (This patient has been studied through the kindness of Dr. C. P. Katsampes.) This fluorescent material was identified as anthranilic acid by chromatographic methods ${ }^{3}$, isolation from the patient's urine, and by spectroscopic techniques. The $R_{F}$ of this fluorescent material was 0.90 in butanol : acetic acid : water, $1: 1: 5$, in agreement with the $R_{F}$ of a known sample of anthranilic acid. The melting point of the material isolated $\left(144-146^{\circ}\right)$ and the absorption spectrum are identical with comparable data reported in the literature for anthranilic acid.

Oral administration of $1 \cdot 6 \mathrm{gm}$. of L-tryptophan led to increased urinary excretion of anthranilic acid as well as to the excretion of other intermediary metabolites of tryptophan.

On the basis of the available knowledge concerning tryptophan metabolism it was reasoned that anthranilic acid was most likely to accumulate in excessive amounts under conditions of riboflavin deficiency. This point of view has recently been confirmed by the work of Charconnet-Harding et al. ${ }^{4}$ and Mason ${ }^{5}$. In order to test the validity of this postulate, the patient in question was treated with massive doses of riboflavin per os (200 mgm. per day for 17 days and then $100 \mathrm{mgm}$. per day for 13 days). Although no change in the hæmatological status was observed even after one month under this therapeutic regimen, there appeared to be a decrease in the amount of anthranilic acid excreted.

Specimens from eight additional cases have been made available to us and in all instances anthranilic acid could be found in the urine. (Specimens of urine from cases studied elsewhere were furnished through the kindness of Drs. I. A. B. Cathie, L. K. Diamond, E. Freshman and C. H. Smith.) In one case (specimen and information on the case furnished by Dr. L. K.
Diamond) experiencing hæmatological improvement nine weeks after splenectomy, anthranilic acid was still detectable in the urine. Urinary specimens collected at random on the pædiatric ward revealed no case in which anthranilic acid was detectable in the urine.

The findings reported here are suggestive of an inborn error in tryptophan metabolism. The relationship of this metabolic disturbance to the co-existing anæmia has, as yet, not been elucidated. Studies aimed at exploring this point are now in progress. The genetic disturbance, if such exists, may be pleiotropic in nature. None of the members of the immediate family of the patient studied was found to excrete the metabolite in question. Details of this work will be published elsewhere.

This paper is based in part on work performed under contract with the U.S. Atomic Energy Commission at the University of Rochester Atomic Energy Project, Rochester, New York.

\section{K. I. Alitman \\ Gerald Miller}

Divisions of Experimental Radiology

and Radiation Biology,

University of Rochester

School of Medicine and Dentistry, Rochester, New York.

$$
\text { July } 8 .
$$

${ }^{1}$ Diamond, I. K., and Blackfan, K. D., Amer. J. Dis. Child, 56, 46t (1938).

${ }^{2}$ Cathie, I. A. B., Arch. Dis. Childh., 25, 313 (1950).

${ }^{3}$ Dalgliesh, C. E., Biochem. J., 52, 3 (1952).

- Charconnet-Harding, F., Dalgliesh, C. E., and Neuberger, A., Bio chem. J., 58, 513 (1953).

${ }^{5}$ Mason, M., J. Biol. Chem., 210, 513 (1953).

\section{Quantitative Aspects of the Indirect Action of $\mathbf{X}$-Radiation at Various Concentrations on $E$. coli}

THE lethal effects of irradiations with $\mathrm{X}$-rays on $E$. coli have been studied. Our observations were made on bacteria dried, or suspended either in 2 per cent broth or saline solution, at bacterial densities of $10^{-1}$ to $10^{-10} \mathrm{gm} . / \mathrm{ml}$. Some experiments were also made by adding $10^{-3} M$ cysteine to the solutions. An X-ray tube was used operating at $110 \mathrm{kV}$., and $4 \mathrm{~m}$.amp., at a dose-rate of $36 \mathrm{r}$./min., without any additional filter.

The overall configuration of the curves paralleled that observed by other authors on tobacco mosaic virus $^{1}$, rabbit papilloma virus ${ }^{2}$ and $S-13$ coli phage ${ }^{3}$. Our results can be partly explained on the basis of widely accepted theories. On the dry bacteria and strongly concentrated suspensions, the effect is only direct; as the concentration is diminished (in the absence of broth), both direct and indirect effects occur. If the suspending medium contains cysteine, the indirect action is reduced; it disappears if the medium contains broth.

There is no clear explanation of the observation that the dose giving $36 \cdot 8$ per cent survival $\left(D_{37}\right)$ is independent of the bacterial concentration, at extremely diluted cell suspensions. The hypothesis (Lea', p. 317), that the 'death' of a bacterium is due to a direct effect only, cannot be accepted under the conditions of our experiments. The marked difference between the $D_{37}$ for irradiated dry bacteria and for those in water, as well as the chemical protection, necessarily require an explanation of the absence of 